\title{
THE SWEDISH RATING LIST
}

\author{
ICCA Communication \\ Torbjörn Jansson and Hans Pahlén
}

Continuing our policy, this issue contains the latest version of the Swedish Rating List. It contains two new entries. The rating of the new D+ program from Saitek is a little disappointing: 15 points below the old D program. A better start has been made by the American PC program Rex Chess v. 2.3 from Larry Kaufman, although the 40 games on which it is rated is rather low.

All games were played at 40 moves in two hours by members of the Swedish Chess Computer Association (SSDF). As usual, '+ -' denotes the half-width of a 95\% confidence interval on the rating, 'games' stands for the number of games on which the rating is based and 'against' stands for the average rating of opponents. By elementary methods wider $(>95 \%)$ or narrower $(<95 \%)$ confidence intervals may be derived by referring to Gaussian statistics.

\begin{tabular}{|c|c|c|c|c|c|c|}
\hline$\#$ & Name & rating & +- & games & win $\%$ & against \\
\hline $\begin{array}{l}1 . \\
2 . \\
3 . \\
4 . \\
6 . \\
7 . \\
8 . \\
9 . \\
10 . \\
10 . \\
12 . \\
13 . \\
14 . \\
15 . \\
16 . \\
17 . \\
18 . \\
20 . \\
21 . \\
22 . \\
23 . \\
24 . \\
25 . \\
26 . \\
27 . \\
28 . \\
29 \\
30 . \\
31 . \\
32 . \\
33 . \\
34 . \\
35 . \\
35 \\
37 . \\
37 . \\
37 . \\
40 . \\
41 . \\
42 . \\
43 . \\
45 . \\
46 . \\
47 . \\
48 . \\
49 . \\
50 . \\
51 . \\
53 . \\
54 . \\
55 . \\
56 . \\
57 . \\
58 . \\
59 . \\
\end{array}$ & 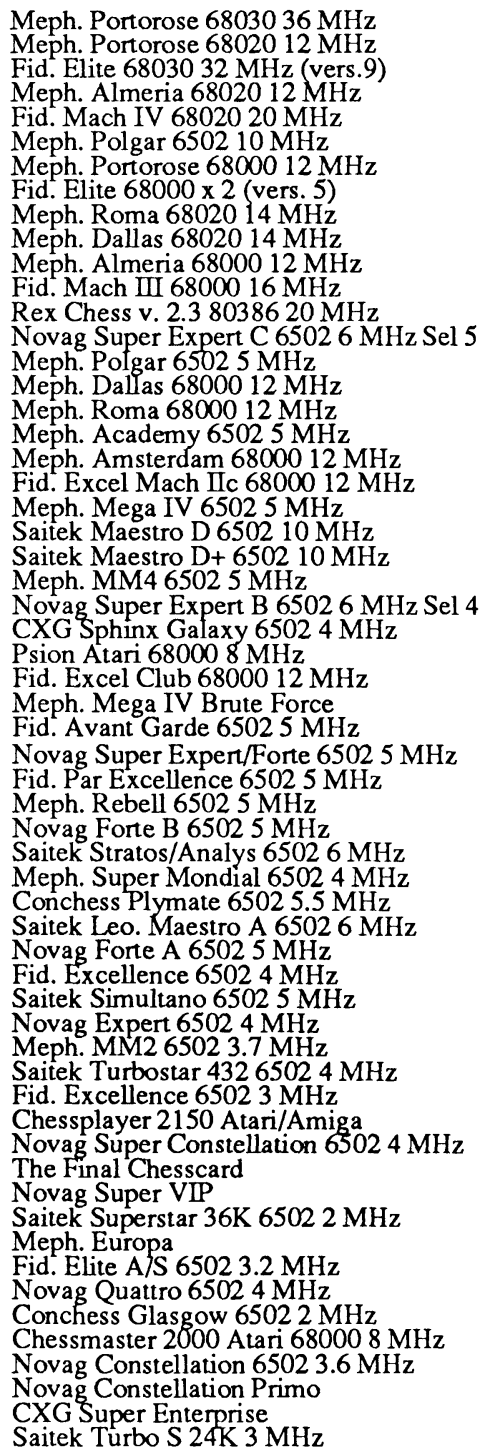 & $\begin{array}{l}2220 \\
2110 \\
2102 \\
2070 \\
2070 \\
2056 \\
2019 \\
2007 \\
2002 \\
1994 \\
1994 \\
1983 \\
1976 \\
1965 \\
1959 \\
1949 \\
1944 \\
1910 \\
1900 \\
1894 \\
1892 \\
1891 \\
1876 \\
1875 \\
1874 \\
1859 \\
1850 \\
1827 \\
1824 \\
1805 \\
1801 \\
1793 \\
1786 \\
1785 \\
1777 \\
1777 \\
1776 \\
1776 \\
1776 \\
1765 \\
1762 \\
1758 \\
1737 \\
1731 \\
1722 \\
1709 \\
1694 \\
1669 \\
1656 \\
1647 \\
1646 \\
1638 \\
1627 \\
1625 \\
1622 \\
1606 \\
1599 \\
1513 \\
1433\end{array}$ & 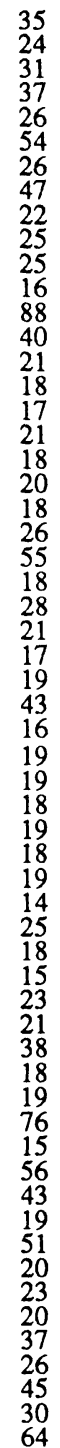 & $\begin{array}{r}252 \\
526 \\
313 \\
227 \\
457 \\
105 \\
467 \\
139 \\
648 \\
489 \\
484 \\
1250 \\
40 \\
192 \\
665 \\
927 \\
1090 \\
726 \\
960 \\
754 \\
908 \\
444 \\
100 \\
978 \\
389 \\
694 \\
1065 \\
889 \\
168 \\
1156 \\
817 \\
831 \\
900 \\
835 \\
910 \\
863 \\
1493 \\
511 \\
939 \\
1327 \\
567 \\
684 \\
208 \\
998 \\
875 \\
53 \\
1354 \\
99 \\
165 \\
854 \\
117 \\
779 \\
560 \\
752 \\
225 \\
472 \\
149 \\
331 \\
75\end{array}$ & 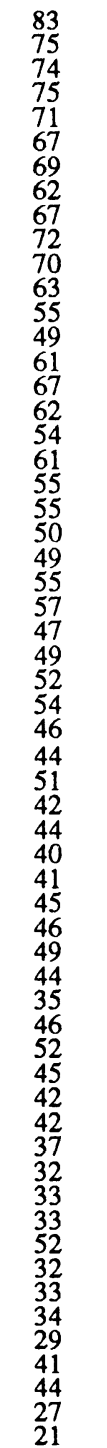 & $\begin{array}{l}1955 \\
1917 \\
1916 \\
1880 \\
1917 \\
1931 \\
1875 \\
1921 \\
1874 \\
1830 \\
1845 \\
1886 \\
1940 \\
1969 \\
1882 \\
1827 \\
1860 \\
1883 \\
1820 \\
1857 \\
1853 \\
1888 \\
1879 \\
1839 \\
1825 \\
1880 \\
1853 \\
1812 \\
1792 \\
1832 \\
1844 \\
1786 \\
1846 \\
1829 \\
1851 \\
1842 \\
1809 \\
1803 \\
1784 \\
1811 \\
1873 \\
1788 \\
1720 \\
1766 \\
1779 \\
1763 \\
1786 \\
1802 \\
1782 \\
1772 \\
1634 \\
1771 \\
1755 \\
1740 \\
1781 \\
1670 \\
1645 \\
1687 \\
1658\end{array}$ \\
\hline
\end{tabular}

We repeat the announcement by Mr. Göran Grottling of his up-to-date service, the Swedish Rating Service, offering Swedish Rating Lists (8 issues per year) for 120 SEK or alternate issues for 60 SEK. The equivalent in bank notes is also acceptable. If you go through Bank or Giro, please add 40 SEK to the amount stated, this being the equivalent of banking fees, so effectively rendering the payment net to the recipient. The lists will include all results and now cover 6 pages per issue. Dues are payable to SSDF, Swedish postal giro no 418772 0 , accessible through any bank. The information is based on about 300 tournament games each month. All other information may be obtained by writing to Göran Grottling, Diabasvägen 3, S 43700 Lindome / Sweden. 